\title{
EESTI KESKAJA UURIMINE 21. SAJANDIL
}

\author{
Inna PÕLTSAM-JÜRJO ${ }^{\mathrm{a}}$ ja Anti SELART ${ }^{\mathrm{b}}$
}

\footnotetext{
a Tallinna Ülikool, humanitaarteaduste instituut, ajaloo, arheoloogia ja kunstiajaloo keskus, Narva mnt 25, 10120 Tallinn, Eesti; inna.jurjo@tlu.ee

b Tartu Ülikool, humanitaarteaduste ja kunstide valdkond, ajaloo ja arheoloogia instituut, Ülikooli 18, 50090 Tartu, Eesti; anti.selart@ut.ee
}

\begin{abstract}
Artikkel annab ülevaate Eesti keskaja ajaloo uurimise tähtsamatest tulemustest ja suundumustest viimasel kahel kümnendil. Vaadeldakse, millised uurimisvaldkonnad on osutunud selle aja jooksul kõige viljakamateks ning millised on loonud sobiva platvormi nii Eesti-siseseks kui ka rahvusvaheliseks koostööks. Samuti tuuakse välja teemad, mis on varasemaga võrreldes jäänud tagaplaanile või mille potentsiaali pole suudetud uurimistöös realiseerida. Artiklis tutvustatakse aktiivseid uurimisasutusi ja uurimistöö rahastamist, ühtlasi esitatakse joonealustes asjakohaste publikatsioonide rikkalik bibliograafia.
\end{abstract}

Eesti tänapäeva medievistika ${ }^{1}$ arengu jaoks olid usutavasti just 1990. aastad otsustavad ning pöördelised. Talurahva ja põllumajanduse ajaloo uurimine, millele oluline osa keskaja uurijaist Eestis nii enne kui ka pärast Teist maailmasõda keskendus, oli end selleks ajaks suuresti ammendanud. Pealegi olid välismaa arhiivid, mis oleks võinud pakkuda allikmaterjali osas lisa, nõukogude ajal raskesti ligipääsetavad. Tollased noored ajaloolased Jüri Kivimäe ja Priit Raudkivi olid oma kandidaaditööd juba 1981. ja 1987. aastal kaitsnud teemadel, mis käsitlesid pigem „saksa“ Liivimaad. Laiem kui kitsalt kohalik vaatepiir iseloomustas juba Eesti vabariigi taassünni eel ka Eesti keskaja kunsti uurimist. ${ }^{2}$ Eriti ärgitas 1980. aastate lõpul ja 1990. aastatel tollaseid üliõpilasi keskaegse ja 16. sajandi Liivimaaga seotud teemasid uurima Jüri Kivimäe ${ }^{3}$ õppejõutöö Tartu Ülikoolis; aegade muutudes avanesid ka võimalused

1 Vt ka Kala, T. Eesti vanem ja uuem medievistika. - Kõnetav kultuur. Toim R. Veidemann, Õ. Kepp. Eesti Keele Sihtasutus, Tallinn, 2011, 163-178. Siinne artikkel keskendub kirjalikele allikatele tuginevale ajaloouurimisele ega sea oma eesmärgiks käsitleda samavõrra põhjalikult keskaja kunstiajalugu ja arheoloogiat. Vt Randla, A., Mänd, A. Keskaja visuaalkultuuri uurimisseisust Eestis ja Lätis. - Kunstiteaduslikke Uurimusi, 2016, 25, 1-2, 7-22; Archaeological research in Estonia 18652005. Ed. by V. Lang, M. Laneman. (Estonian Archaeology 1.) Tartu University Press, Tartu 2006.

2 Vt nt Ars Estoniae medii aevi grates Villem Raam viro doctissimo et expertissimo. Toim K. Alttoa. Eesti Muinsuskaitse Selts, Tallinn, 1995.

3 Kreem, J. Jüri Kivimäe, uurija ja õpetaja. - Vana Tallinn, 2017, 28 (32), 11-28. 
pikemalt edasi õppida või end lühemalt täiendada laias maailmas - Saksamaal, Prantsusmaal, Ungaris, Soomes. Just sel perioodil hakkas kujunema Eesti keskaja uurijate pere, mille liikmed valdavalt kaitsesid oma doktoritööd juba uuel sajandil. Ühendab neid eelkõige uurimisobjekt keskaegse ja 16. sajandi Liivimaa näol, mitte tingimata koolkondlikkus näiteks kirjutamisviisi või ühiste teoreetiliste autoriteetide mõttes.

Hoolimata kriitilistest häältest ${ }^{4}$ on püsima jäänud traditsioon ühendada 16. sajandi esimese poole ajalugu varasemate sajanditega „Eesti keskajaks“, seda vähemalt eestikeelseis publikatsioonides. See on kindlasti õigustatud, eriti kuna sageli tuleb Liivimaa hiliskeskaja uurimisel kasutada retrospektiivselt varauusaegseid allikaid Liivimaa sõja eelsest perioodist. Kui Eesti ja Läti professionaalse ajalooteaduse sünd sada aastat tagasi jagas keskaegse Liivimaa uurimise pahatihti Eesti ja Läti „pooleks“, siis tänapäeva uurijad - tingituna ka küsimuseasetuste muutumisest - on püüelnud selles osas taasühinemise poole ja kaasanud üha enam ka Läti ala materjali. Eesti ja Läti keskaja uurimisel on alati olnud ühine keel: kuni 2000. aastateni saksa keel, mille kõrvale aga nüüdseks on publikatsioonides domineerivaks tõusnud inglise keel.

\section{LIIVIMAA RISTISÕDADE AJALUGU}

20. sajandi lõpukümnesse langes huvitõus Elbe jõest itta jääva Euroopa ajaloo vastu kogu maailmas, ${ }^{5}$ samuti „uue“ ristisõdade ajaloo esilekerkimine. ${ }^{6}$ Viimane tähendab 1970. aastate ingliskeelsest ajalooteadusest alanud pööret ristisõdade kui nähtuse mõistmises: enam ei keskendutud üksnes Pühale Maale suundunud ja traditsiooniliselt nummerdatud ristiretkedele. Sai selgeks, et ristisõjaideoloogia oli oluline tegur ka Skandinaavias ja Baltikumis ning et ristisõjaideoloogia ja -teoloogia jäid oluliseks vähemalt keskaja lõpuni. Läänemere maades oli selle uue vaatenurga juurutamisel keskne roll Taani ajaloolastel. ${ }^{7}$ Laiemalt seostus Liivimaa ajalugu ristisõdade kaudu Euroopa üldajalooga, mille abil ka Eesti keskaja uurijad leidsid olulise väljundi rahvusvahelisele areenile. ${ }^{8}$ See soodustas keskendumist 13 . sajandi ajaloole ja samuti nendele Liivimaa ajaloo teemadele, mis olid tihedamalt seotud või kergemini seostatavad ristisõdadega, nagu Saksa ordu ajalugu. ${ }^{9}$ Märkimisväärne on olnud uurijate tähelepanu Henriku

4 Berendsen, V. Eesti ajaloo periodiseerimisest maailma ajaloo taustal: Uusaegne, moderne, kapitalistlik. - Looming, 1994, 11, 1531-1552.

5 Raffensperger, C. Reimagining Europe: An outsider looks at the medieval East-West divide. - The medieval networks in East Central Europe: Commerce, contacts, communication. Ed. by B. Nagy et al. Routledge, London, 2019, 11-24.

6 Kaljundi, L. Püha sõja otsinguil: Ristisõdade uuemast historiograafiast Euroopas ja Läänemeremaades. - Ajalooline Ajakiri, 2007, 2, 193-223.

7 Lind, J. H., Jensen, C. V., Jensen, K. V., Bysted, A. L. Taani ristisõjad - sõda ja misjon Läänemere ääres. Tlk I. Rüütli, K. Kroon. Argo, Tallinn, 2007.

8 Crusade and conversion on the Baltic frontier 1150-1500. Ed. by A. V. Murray. Ashgate, Aldershot, 2001; The clash of cultures on the medieval Baltic frontier. Ed. by A. V. Murray. Ashgate, Farnham, 2009.

9 Vt nt Kreem, J. The town and its lord: Reval and the Teutonic Order (in the fifteenth century). Ilo, Tallinn, 2002; Kreem, J. Wie landfremd war der Deutsche Orden in Livland? Regionale und interregionale Beziehungen des Deutschen Ordens im 16. Jahrhundert. - Herrschaft, Netzwerke, 
Liivimaa kroonika vastu. ${ }^{10}$ Eesti uurijad on nüüdseks andnud oma panuse ka suuremaid alasid kui pelgalt kohalikku regiooni käsitlevatesse diskussioonidesse. ${ }^{11}$

Liivimaa käsitlemine ristisõjapiirkonnana on tagantjärele ühtlasi osutunud tegusaks turundusvõtteks, mis on toetanud Eesti keskaja-uurijate tööde rahvusvahelist levikut. Samas on see vaatenurk end näidanud ka piirava tegurina ja praeguseks on end üsna selgesti ilmutanud selle kitsaskohad. Isegi 13. sajandil ei olnud kõik Liivimaal toimunu ristisõda või ristiretkede tulemus. ${ }^{12}$ Veelgi selgemalt on „Liivimaa ristisõja“ kui kogu keskaja Liivimaa üldnimetaja sobimatus näha hilisematel sajanditel, eriti arvestades sagedast soovi pikendada Baltimaade ristisõdade ajalugu kuni Liivimaa Saksa ordu likvideerimiseni 1560. aastatel. Juhan Kreemi sõnul: „Ristisõda mängis kindlasti otsustavat osa keskaegse Liivimaa kujunemisloos ja usu kaudu põhjendatud sõjad jäid Liivimaa ühiskonnas oluliseks ka hiljem. Kuid maa ei olnud pidevalt vastasseisus oma paganlike ja õigeusklike naabritega. Samuti ei olnud sõda ja vallutus Saksa ordu ainus olemisviis: ta pööras palju tähelepanu ka omandatud alade haldamisele. Veelgi enam, mitte iga Saksa ordu sõjaline ettevõte polnud risti-

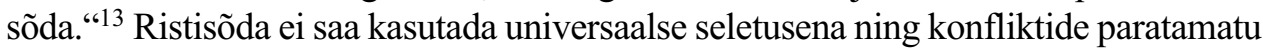
toonitamise kaudu jätab see varju põhilise osa Liivimaa elust ja selle maa rahva suhetest naabritega, kus tooni andis rahumeelne, vastastikku kasulik läbikäimine.

Ristisõja üldteemaga pole alati lihtne sobitada ka Liivimaa sisesuhete ajaloo uurimist. Kuigi varasemast, eelkõige baltisaksa uurimistraditsioonist lähtuvad arusaamad Liivimaa ühtsusest kui eesmärgist ja paavstide kui „välisjõu“ ohtlikust sekkumisest pole päriselt hääbunud, ${ }^{14}$ on Liivimaa poliitilist (ja mitte ainult poliitilist) ajalugu hakatud julgemalt nägema laiemates, kogu Läänemere piirkonda ja tervet Euroopat hõlmavates seostes. ${ }^{15}$ Need seosed haaravad ka isikutevahelisi sidemeid,

Brüder des Deutschen Ordens in Mittelalter und Neuzeit. Hrsg. v. K. Militzer. (Quellen und Studien zur Geschichte des Deutschen Ordnes, 72.) VDG, Weimar, 2012, 149-158.

${ }^{10}$ Crusading and chronicle writing on the medieval Baltic frontier: A Companion to the Chronicle of Henry of Livonia. Ed. by M. Tamm, L. Kaljundi, C. S. Jensen. Ashgate, Farnham, 2011.

${ }^{11}$ Tamm, M. How to justify a crusade? The conquest of Livonia and new crusade rhetoric in the early thirteenth century. - Journal of Medieval History, 2013, 39, 431-455; Selart, A. Livonia, Rus' and the Baltic crusades in the thirteenth century. (East Central and Eastern Europe in the Middle Ages, 450-1450, 29.) Brill, Leiden, Boston, 2015; Kaljundi, L. Livonia as a Mariological periphery: A comparative look at Henry of Livonia's representations of the mother of God. - Livland - eine Region am Ende der Welt? Forschungen zum Verhältnis zwischen Zentrum und Peripherien / Livonia - a Region at the End of the World? Studies on the Relations between Centre and Periphery in the Later Middle Ages. Ed. by A. Selart, M. Thumser. (Quellen und Studien zur baltischen Geschichte, 27.) Böhlau, Köln, 2017, 431-460.

${ }^{12}$ Selart, A. Post hoc oder propter hoc? Eroberung, Einwanderung und Gesellschaftswandel im mittelalterlichen Livland. - Blätter für deutsche Landesgeschichte, 2018, 154, 429-453

${ }^{13}$ Kreem, J. Crusading traditions and chivalric ideals: The mentality of the Teutonic Order in Livonia at the beginning of the sixteenth century. - Crusades, 2013, 12, 234.

${ }^{14}$ Eihmane, E. Livonia and the Holy See in 13 th - early 15th centuries: Centre and periphery of Christendom. - The image of the Baltic: A Festschrift for Nils Blomkvist. Ed. by M. F. Scholz. Gotland University Press, Visby, 2012, 23-40; Raudkivi, P. Tracing social change: The case of Old Livonia. - Nordost-Archiv: Zeitschrift für Regionalgeschichte, 2014, 22, 15-36;

${ }^{15}$ Mäesalu, M. King Wenceslas' relations with the Teutonic Order in light of the dispute over the Archbishopric of Riga (1392-1397). - Journal of Baltic Studies, 2016, 47, 3, 369-383; Mäesalu, M. Liivimaa ja Püha Rooma keisririik 1199-1486. Tartu Ülikooli Kirjastus, Tartu, 2017. 
inimeste, ideede ja eeskujude liikumist, ${ }^{16}$ mis kõik olid laiemad ja mitmetahulisemad nähtused kui vallutusele rõhuasetust paigutav ristisõda. Ka kristianiseerimine hõlmas mitte pelgalt usulisi, vaid samuti õiguslikke ja majanduslikke aspekte. ${ }^{17}$

\section{EESTLASTE AJALUGU}

Suuremate seoste esiletõstmine tähendab ka seniharjutuga võrreldes teist vaatepiiri Eesti minevikule. Traditsioonilise, maailmasõdade vahel juurdunud termini „muistne vabadusvõitlus“ 18 kõrvalejätmine mitme Eesti kutselise keskaja-uurija töödes on aga põhjustanud protesti, mis avaldus eriti kujukalt väitlustes seoses „Eesti ajaloo“ sarja keskaja-köite ${ }^{19}$ ilmumisega 2012. aasta lõpul. Ühe seisukoha järgi: „terminivahetus kujutab endast positsiooni vahetamist, vaatekoha muutmist, asumist väljastpoolt vaatleja seisukohale [...]. [U]ued küsimuseasetused on meil praegusel ajal tihti üldinimlikult, globaalselt, vähemalt üleeuroopaliselt suunitletud [...], aga kohalik emakeelne lugejaskond vajab ka lähivaatelist, kodukohast lähtuvat, enesekeskset ajalookäsitlust“ ${ }^{20}$ Kõlas etteheide, et mainitud raamat „keeldub meile ütlemast, kes olid head ja kes pahad“ “ ${ }^{21}$ Käsitluse üle peetud diskussiooni sisu keskendus aga tollal tegelikult mitte niivõrd keskaegsele Liivimaale, kuivõrd arusaamadele Eesti vallutuseelsest ühiskonnast, selle sisemisest integratsioonist ja poliitilisest korraldusest. Hinnang vallutusele ja selle tähendusele sõltub paratamatult suuresti ettekujutusest kohaliku ühiskonna kohta vallutuse eelõhtul - kuhu paigutub eestlaste „muinasmaa“?22 On tähelepanuväärne, et sellal kui arheoloogid toonitavad muinasaja lõpu Eesti tihedaid sidemeid muu maailmaga, kalduvad kirjalike allikatega töötavad uurijad pigem rõhutama „vana“ ja „uue“ erinevusi. ${ }^{23}$

Liivimaa vallutusjärgse ühiskonna uurimisel on üldiseks suundumuseks tähelepanu pööramine pigem ,saksa“ ja „,mittesaksa“ kihtide integratsioonivõimalustele, sellal kui traditsiooniliselt on ka siin rõhutatud nendevahelist antagonismi. Tiina Kala seadis kahtluse alla termini undeutsch seni omaks võetud etnilise definitsiooni. Kui mõista „mittesakslaste“ all üksnes kitsamalt talupoegi, mitte etnilisi (linna)eest-

${ }^{16}$ Kreem, J. Mobility of the Livonian Teutonic knights. - Making Livonia: Actors and networks in the medieval and early modern Baltic Sea region. Ed. by A. Mänd, M. Tamm. Routledge, New York, London, 2020, 158-169; Tamm, M. Mission and mobility: The travels and networking of Bishop Albert of Riga (c. 1165-1229). - Making Livonia, 17-47; Tamm, M. Tallinna Püha Katariina konvent 13. sajandi dominiiklaste võrgustikes. - Vana Tallinn, 2017, 28 (32), 170-201.

${ }^{17}$ Leimus, I. Iura christianorum - Läti Henriku sõnakõlks või nõks paganate alistamiseks? - Tuna, 2011, 1, 9-19.

${ }^{18}$ Selart, A. Muistne vabadusvõitlus. - Vikerkaar, 2003, 10-11, 108-120.

${ }^{19}$ Eesti ajalugu II: Eesti keskaeg. Toim A. Selart. Tartu Ülikooli ajaloo ja arheoloogia instituut, Tartu, 2012.

${ }^{20}$ Tarvel, E. Eesti rahva lugu. Varrak, Tallinn, 2018, 31-32.

${ }^{21}$ Vahtre, L. Tünnitäis koos kulbitäiega. - Akadeemia, 2013, 4, 722.

${ }^{22}$ Kaljundi, L. Muinasmaa sünd. - Vikerkaar, 2008, 7-8, 98-112.

${ }^{23}$ Vt Jonuks, T., Oras, E., Veldi, M. Mix and match, old and new - material remains of religious practices by Estonian pagans. - Archaeological sites as space for modern spiritual practice. Ed. by J. Leskovar, R. Karl. Cambridge Scholars Publishing, Newcastle upon Tyne, 2018, 90-109; Jonuks, T. Domesticating Europe - Novel cultural influences in the Late Iron Age Eastern Baltic (ilmumas). 
lasi (või -lätlasi), siis omandab „mittesakslasi“ diskrimineeriv seadusandlus hiliskeskaja linnades hoopis teise tähenduse. ${ }^{24}$ Ilmselt on mitmetähendusliku ${ }^{25}$ termini „mittesakslane“ kasutuses aspekte, mida selle võrdsustamine talupoegadega liigselt lihtsustab, ${ }^{26}$ kuid laiem vaade Liivimaa ühiskonnale, mis ei keskendu etnilisele eraldamisele, avab kahtlemata uusi ja olulisi uurimisperspektiive.

Talurahvaajaloo uurimine on võrreldes linnaajalooga jäänud 21. sajandi Eesti ajalooteaduses selgelt tagaplaanile, uusi käsitlusi ilmub vähe; muutunud on uurimisfookus: kui varasemas historiograafias oli peamiselt vaatluse all talurahva maakasutus, koormised ja sotsiaalne kihistumine, siis nüüdisajal on need andnud teed muudele teemadele, nagu eluolu, rahvauskumused ja -tavad, sotsiaalsed suhted, kommunikatsioon jne. Keskaja talurahvaajaloo uurimisel on ajaloolaste kõrval jõuliselt oma sõna ütlemas arheoloogid, kes on seda valdkonda rikastanud nii uudse allikmaterjali kui ka teemadega. ${ }^{27}$ Uute uurimuste ühiseks jooneks on taotlus käsitleda talurahva ajalugu varasemast diferentseeritumalt nii ajas kui ka ruumis, selgitada välja ja kirjeldada piirkondlikke eripärasid, samuti talurahva identiteedi ja eneseteadvuse muutumist ning arengut keskaja jooksul. Vaeslapse ossa on endiselt jäänud keskaja aadli- ja mõisakultuuri uurimine. Arheoloogiliste kaevamiste tulemused on toonud siiski mõnevõrra uusi andmeid mõisate ja/või vasallilinnuste uurimisse. ${ }^{28}$

Keskaja Liivimaa asukoht kristliku maailma äärel, Euroopa perifeerias, ortodoksse Venemaa naabrina on avanud medievistidele paljulubava uurimisperspektiivi, vaatlemaks kahe maailma piiril asumise mõju Liivimaa arengule ja enesekuvandile. Ühest küljest on huvipakkuv, milliseks kujunesid Liivimaa suhted Euroopa keskustega, iseäranis Saksa-Rooma Püha Keisririigiga, ${ }^{29}$ ning kas

${ }^{24}$ Kala, T. Gab es eine „nationale Frage“ im mittelalterlichen Reval? - Forschungen zur baltischen Geschichte, 2012, 7, 11-34; Selart, A. Non-German literacy in medieval Livonia. - Uses of the written word in medieval towns: Medieval urban literacy II. Ed. by M. Mostert, A. Adamska. (Utrecht Studies in Medieval Literacy, 28.) Brepols, Turnhout, 2014, 37-63.

${ }^{25}$ Vt Lenz, W. Undeutsch: Bemerkungen zu einem besonderen Begriff der baltischen Geschichte. - Aus der Geschichte Alt-Livlands: Festschrift für Heinz von zur Mühlen zum 90. Geburtstag. Hrsg. v. B. Jähnig, K. Militzer. (Schriften der Baltischen Historischen Kommission, 12.) Lit, Münster, 2004, 169-184.

${ }^{26}$ Vt nt Mänd, A. Käsitööliste ühiskondlik seisund ja päritolu. - Tallinna ajalugu I: 1561. aastani. Toim T. Kala, T. Tamla. Tallinna Linnaarhiiv, Tallinn, 2019, 249-251.

${ }^{27}$ Vt nt Lang, V. Vakus ja linnusepiirkond Eestis: Lisandeid muistse haldusstruktuuri uurimisele peamiselt Harjumaa näitel. - Keskus - tagamaa - ääreala. Toim V. Lang. Teaduste Akadeemia Kirjastus, Tallinn, Tartu, 2002, 125-169; Valk, H. Estland im 11.-13. Jahrhundert: Neuere Aspekte aus Sicht der Archäologie. - Forschungen zur baltischen Geschichte, 2008, 2, 57-87; Laul, S., Valk, H. Siksälä: A community at the trontiers: Iron Age and medieval. University of Tartu, Institute of History and Archaelogy, Tallinn, Tartu, 2007; Valk, H. Die ethnischen Identitäten der undeutschen Landbevölkerung Estlands vom 13. bis zum 16. Jahrhundert: Ergebnisse der Archäologie. Estnisches Mittelalter. - Sprache - Gesellschaft - Kirche. Hrsg. v. K.-R. Hahn, M. Thumser, E. Winkler. (Schriften der Baltischen Historischen Kommission, 20.) Lit, Berlin, 2015, 55-91.

${ }^{28}$ Kadakas, V. Keskaegne maja Kõue-Triigi mõisa keldrites. - Muinsuskaitse aastaraamat, 2013, 20 21; Hein, A. Stenhus'id, arx'id, torne'd ...: Eesti mõisaarhitektuuri vanim kihistus. Õpetatud Eesti Selts, Tartu, 2016.

${ }^{29}$ Mäesalu, M. Die Steuerforderungen des Heiligen Römischen Reiches an die Kirchenprovinz Riga im 15. Jahrhundert. - Livland - eine Region am Ende der Welt?, 259-282; Maasing, M. Livland und die Reichstage (1520-1555). - Livland - eine Region am Ende der Welt?, 283-312. 
ja kui aktiivne roll oli selles Liivimaal endal, teisalt väärib tähelepanu, kuidas perifeerias asumine mõjutas maa eri seisuste identiteediloomet. Näiteks linnakodanike puhul on välja toodud, et pürjelite, iseäranis hansakaupmeeste lai suhtlusvõrgustik, tihedad perekondlikud ja ametialased sidemed läänepoolsete hansalinnadega oli põhjus, miks Liivimaa linnakodanike regionaalne identiteet kujunes välja suhteliselt hilja, alles 14. sajandi keskpaiku. ${ }^{30}$ Igal juhul näitavad olemasolevad uurimused perifeeria aktiivset rolli keskusega suhete kujundamisel. ${ }^{31}$

\section{KIRIKUAJALUGU}

Väga ulatuslikult on tegeletud keskaja kirikulooga, mis varem oli Eesti teadlastele pakkunud huvi eelkõige maaelanikkonna „kristianiseerituse taseme“ üsna kitsast ja ideoloogiliselt väga tugevasti laetud aspektist. Uurimusi on pühendatud ristimise ja pagana-ristiinimese vastanduse sisule keskajal üldse ja eriti 12.-13. sajandil, mis on näidanud nendegi piiride suuremat paindlikkust ja tinglikkust võrreldes varem arvatuga. ${ }^{32}$ Tähelepanu on pööratud rahvalikule religioonikäsitlusele, ${ }^{33}$ mis on kaasa toonud loobumise ettekujutusest, nagu olnuks katoliikluse ja kiriku mõju Liivimaa keskaegsele talurahvale väga piiratud. Rahvausu uurimisel on kirjalike allikate kõrval taas kord oluliseks informatsiooni jagajaks saanud arheoloogiline leiuaines ning ajaloolaste kõrval on just arheoloogid selles valdkonnas tõhusalt panustanud. Uuritud on selliseid kirikuinstitutsioone nagu piiskopkonnad, ${ }^{34}$ vaimulikud ordud, ${ }^{35}$ kihelkon-

${ }^{30}$ Selart, A. Sie kommen, und sie gehen: Zentrale Orte, Randgebiete und die Livländer im Mittelalter. Livland - eine Region am Ende der Welt?, 27-60.

${ }^{31}$ Kreem, J. Eine Peripherie mit Zentrumsambitionen? Zum Selbstverständnis des Deutschen Ordens in Livland im 16. Jahrhundert - Livland - eine Region am Ende der Welt?, 415-428.

${ }^{32}$ Leimus, I. Läänemere kristlikud paganad. - Tuna, 2009, 4, 5-22; Jonuks, T., Kurisoo, T. To be or not to be ... a Christian: Some new perspectives on understanding the Christianisation of Estonia. Folklore: Electronic Journal of Folklore, 2013, 55, 69-97; Kala, T. Verkündigung und Kreuzpredigt in und für Livland im 13. Jahrhundert. - Leonid Arbusow (1882-1951) und die Erforschung des mittelalterlichen Livland. Hrsg. v. I. Misāns, K. Neitmann. (Quellen und Studien zur baltischen Geschichte, 24.) Böhlau, Köln, Weimar, Wien, 2014, 187-207.

${ }^{33}$ Valk, H. Estonian popular religion c. 1250-1700: Sources, research and problems. - Estland, Lettland und westliches Christentum / Eestimaa, Liivimaa ja Lääne kristlus. Hrsg. v. S. Rutiku, R. Staats. Friedrich Wittig Verlag, Kiel, 1998, 91-102; Kala, T. Rural society and religious innovation: Acceptance and rejection of Catholicism among native inhabitants of medieval Livonia. - The clash of cultures on the medieval Baltic frontier, 169-190; Põltsam-Jürjo, I. Ein Beitrag zur Kenntnis des religiösen Lebens der autochthonen Bevölkerung Estlands im 13.-16. Jahrhundert. - Die Kirche im mittelalterlichen Livland. Hrsg. v. R. Biskup, J. Götz, A. Radziminski. (Ecclesia clerusque temporibus medii aevi, 5.) Wydawnictwo Naukowe Uniwersytetu Mikolaja Kopernika, Toruń, 2019, 197-216.

${ }^{34}$ Saare-Lääne piiskopkond: Artiklid Lääne-Eesti keskajast / Bistum Ösel-Wiek: Artikelsammlung zum Mittelalter in Westestland. Toim Ü. Paras. Läänemaa Muuseum, Haapsalu, 2004.

${ }^{35}$ Tamm, M. Communicating crusade: Livonian mission and the Cistercian network in the thirteenth century. - Ajalooline Ajakiri, 2009, 3-4, 341-372; Kala, T. Jutlustajad ja hingede päästjad: Dominiiklaste ordu ja Tallinna Püha Katariina konvent. (Acta Universitatis Tallinnensis: Humaniora; 
nad, ${ }^{36}$ samuti vaimulikkonda. ${ }^{37}$ Keskaegsete pühakodade kohta on ilmunud uuenduslikke erikäsitlusi, näiteks Tartu Jaani kirikust, samuti Tartu toomkirikust; nende puhul pole keskendutud mitte ainult ehitus- ja kunstiajaloolistele aspektidele, vaid hõlmatud on ka poliitilist ja sotsiaalajalugu jm. ${ }^{38}$ Terve hulk uurimusi on pühendatud reformatsioonile, ${ }^{39}$ on loobutud „katoliikluse“ ja „luterluse“ teravast vastandamisest 16. sajandi esimese poole Liivimaal ning pigem nähtud religioonikäsitluse uuenemises pikaajalist protsessi. ${ }^{40}$ Iseäranis luterliku reformatsiooni 500. aastapäeva tähistamine 2017. aastal tõstis reformatsiooniajaloo Eestis tugevalt fookusesse. Nüüdisajale on eelkõige iseloomulik loobumine taotlusest üldistavale, kõikehõlmavale käsitlusele, vaid keskendutud on luterliku reformatsiooni mõju eri tahkude lahkamisele. Esile tõstetakse regioonideülese suhtluse tähtsust, samuti mitmesuguste võrgustike kandvat osa Liivimaa reformatsiooniliikumises. Sotsiaalsete mõjude hindamisel on selgunud, et ehkki uue õpetuse ideed ületasid Liivimaal levides seisuslikke ja etnilisi piire, ei tähendanud see ometi seisusepiiride ähmastumist või nõrgenemist, pigem näitavad uurimused nende süvenemist. Samuti ei saa ühemõtteliselt rõhutada reformatsiooni rolli eesti keele arendamisel: paralleelselt eestikeelse raamatutrüki algusega $^{41}$ tõi emakeelse jumalateenistuse nõue kaasa koguduste etnilise eraldumise. ${ }^{42}$

Tallinna Linnaarhiivi toimetised, 13). Tallinna Ülikooli Kirjastus, Tallinn, 2013; Tamm, M. Tallinna Püha Katariina konvent.

${ }^{36}$ Valk, H. On the origins of churches and churchyards in Southern Estonia: The evidence from early grave finds. - Baltic Journal of Art History, 2017, 13, 99-129; Selart, A. Miks on Eesti kihelkonnad nõnda suured? - Humanitaarteadused ja kunstid 100-aastases rahvusülikoolis. Toim R. Altnurme. Tartu Ülikooli Kirjastus, Tartu, 2019, 58-66.

${ }^{37}$ Maasing, M. Liivimaa toomhärrad reformatsiooniajastu alguskümnendeil (1523-1566). - Reformatsioon - tõlked ja tõlgendused. Toim P. Lotman. (Eesti Rahvusraamatukogu toimetised, 16.) Eesti Rahvusraamatukogu, Tallinn, 2019, 11-50; Maasing, M. Saare-Lääne toomhärrad piiskop Peter Wetbergi ajal (1471-1491). - Läänemaa Muuseumi toimetised, 2019, 22, 37-73.

${ }^{38}$ Alttoa, K. Tartu Jaani kirik. Muinsuskaitseamet, Tallinn, 2011; Tartu toomkirik: Katedraal. Raamatukogu. Muuseum. Toim M. Raisma, K. Andreson. Tartu Ülikooli muuseum, Tartu, 2018. Vt ka Markus, K., Kreem, T.-M., Mänd, A. Kaarma kirik. Muinsuskaitseamet, Tallinn, 2003.

${ }^{39}$ Kreem, J. Die livländische Reformation im Spiegel der estnischen Geschichtswissenschaft. - Die Baltischen Lande im Zeitalter der Reformation und Konfessionalisierung: Livland, Estland, Ösel, Ingermanland, Kurland und Lettgallen: Stadt, Land und Konfession 1500-1721. (Katholisches Leben und Kirchenreform im Zeitalter der Glaubensspaltung, 72.) Aschendorff, Münster, 2012, 99-121.

${ }^{40}$ Põltsam, I. Reformatsiooni mõju argielule Liivimaal. - Tuna, 2003, 3, 13-24; Kala, T. Kirikuelu ümberkorraldamine Tallinnas 1520. aastatel ning selle majanduslikud ja sotsiaalsed tagamaad. - Tuna, 2007, 3, 10-26; Kreem, J. Liivimaa ja Augsburgi Interim 1548: Lisandusi teadmistele reformatsiooni levikust Baltikumi. - Tuna, 2011, 4, 6-16; Kreem, J. Die Religionsfrage auf den livländischen Ständeversammlungen 1522-1558. - Preussen und Livland im Zeichen der Reformation. Hrsg. v. A. Mentzel-Reuters, K. Neitmann. (Tagungsberichte der Historischen Kommission für ost- und westpreussische Landesforschung, 28.) Verlag fibre, Osnabrück, 2014, 183-197; Maasing, M. Die Reformationsversuche im Erzbistum Riga in den 1540er und 1560er Jahren. - Die Kirche im Mittelalterlichen Livland, 245-272; Kala, T. Mõnda reformatsioonimuutuste eeldustest Tallinnas: jutlustajad, ametnikud ja raamatud. - Reformatsioon - tõlked ja tõlgendused, 51-70.

${ }^{41}$ Kivimäe, J. Eestikeelsest trükisest anno 1525. - Eesti vanimad raamatud Tallinnas / Die ältesten estnischen Bücher in Tallinn (Reval). Toim L. Kõiv jt. Eesti Rahvusraamatukogu, Tallinn, 2000, 13-61.

${ }^{42}$ Kala, T. Keeled ja nende kõnelejad keskaegses Tallinnas: edenemine või taandareng? - Tuna, 2004, 2, 8-22. 


\section{LINNAAJALUGU JA KULTUURIAJALUGU}

Eesti keskaja ajaloo üks kõige viljakam uurimisvaldkond 21. sajandil on olnud kahtlemata linnaajalugu. Selle tõenduseks on juba ainuüksi ilmunud teaduskirjanduse artiklite, monograafiate, kogumike ja üldkäsitluste - arv ja maht. Linnaajalugu on ühtlasi veel üks viljakas platvorm koostööks teiste maade ajaloolastega, kui mainida kas või linnaajaloo eri aspektidele pühendatud konverentse koostöös peamiselt Saksa, Läti ja Leedu ajaloolastega ning Baltikumi ajalooga tegelevate institutsioonidega ${ }^{43}$ Peamiselt allikate iseloomust tingituna on pigem linnadega tegelenud ka keskaja majandusajaloo uurijad. ${ }^{44}$ Erinevalt muudest valdkondadest on keskaja linnaajaloo uurimine jõudnud ka üldistava enesekaemuseni: tehtud tööst ja peamistest suundumustest on koostatud historiograafilisi ülevaateid. ${ }^{45}$

Linnaajaloolist uurimistööd soodustab kindlasti suurepärase kirjalike allikate baasi olemasolu, eeskätt Tallinna Linnaarhiivi kogude näol, ent palju olulist infot siinsete linnade kohta on andnud viimaste aastakümnete linnaarheoloogilised kaevamised. Nende põhjal on valminud kaalukaid uurimusi linnade rajamise ja arengu, kultuurikontaktide, elanikkonna ja eluolu kohta. ${ }^{46}$ Arheoloogiliste leidude potentsiaali linnajaloo uurimisel demonstreerib hästi 2018. aastal Tallinnas Jahu tänava kaevamistel välja tulnud erakordne hiliskeskaegne leiumaterjal, ${ }^{47}$ mis sunnib ümber hindama või korrigeerima mitmeid seniseid ettekujutusi keskaja linnaelust. Nii

${ }^{43} \mathrm{Nt}$ 2000. aastal Carl-Schirren-Gesellschafti korraldatud Balti linnaajaloo seminari kajastab kogumik: Städtisches Leben im Baltikum zur Zeit der Hanse. Hrsg. v. N. Angermann. (Baltische Seminare, 10.) Carl-Schirren-Gesellschaft, Lüneburg, 2003; 2012. aastal Riias toimunud Balti linnaajaloo konverentsi kajastab kogumik: Stadtgeschichte des Baltikums oder baltische Stadtgeschichte? Annäherung an ein neues Forschungsfeld zur baltischen Geschichte. Hrsg. v. H. Hein-Kircher, I. Misāns. (Tagungen zur Ostmitteleuropaforschung, 33.) Herder-Institut, Marburg, 2015.

${ }^{44}$ Leimus, I. Eesti majandusajaloo historiograafiast: Keskaja kaubandus. - Ajalooline Ajakiri, 2001, 1-2, 25-45; Eesti majandusajaloo historiograafiast II: Keskaja käsitöö. - Ajalooline Ajakiri, 2002, 3, 5-20; Eesti majanduse historiograafiast III: Keskaja linnade mündindus, finantsid ja majandamine. - Ajalooline Ajakiri, 2007, 1, 75-91; Leimus, I. The Baltic region. - Survey of numismatic research 2008-2013. Ed. by C. Arnold-Biucchi, M. Caccamo-Caltabiano. (International Association of Professional Numismatists, Special Publication, 16.) International Association of Professional Numismatists, Taormina, 2015, 436-441.

${ }^{45}$ Russow, E. Quo vadis, Eesti linnaarheoloogia? - Vana Tallinn, 2012, 23, 12-60; Pärn, A. Die Gründungsstädte am Beispiel Estlands - Problemstellungen. - Mitteilungen der Deutschen Gesellschaft für Archäologie des Mittelalters und der Neuzeit, 2014, 27, 105-112; Kreem, J. Was ist Stadtgeschichte in Estland. - Stadtgeschichte des Baltikums oder baltische Stadtgeschichte?, 61-74.

${ }^{46}$ Valk, H. The genesis of Viljandi (Fellin): Archaeological data. - Riga und der Ostseeraum: Von der Gründung 1201 bis in die Frühe Neuzeit. Hrsg. v. I. Misāns, H. Wernike. (Tagungen zur Ostmitteleuropa-Forschung, 22.) Herder Institut, Marburg 2005, 95-108; Haak, A. Viljandi linna kujunemisest peamiselt arheoloogiliste allikate põhjal. - Narva Muuseumi toimetised, 2005, 5, 17 28; Haak, A., Russow, E. On the development of the town of Viljandi in the light of earliest archaeological find complexes. - Estonian Journal of Archaeology, 2013, 17, 57-86.

${ }^{47}$ Russow, E., Randoja, K., Bernotas, R., Tvauri, A., Rammo, R., Reppo, M., Ratas, J., Kreem, J., Lõugas, L. A late medieval treasure trove of Tallinn: Salvage excavations of the 15th-century landfill between the Jahu and Väike-Patarei streets. - Archaeological Fieldwork in Estonia 2018. Ed. by E. Russow, A. Haak. Muinsuskaitseamet, Tallinn, 2019, 185-218. 
arheoloogid kui ka kunsti- ja arhitektuuriajaloolased on vaadelnud keskaja linnaruumi, linnakindlustuste ja hoonestuse arengulugu ning avaldanud uurimistulemusi erialaartiklite kõrval ka kaalukates üldkäsitlustes. ${ }^{48}$

Kirjalikele allikatele tuginevatele linnajaloolistele uurimustele on iseloomulik, et ühest küljest keskenduvad need peamiselt Tallinna ajaloole, teisest küljest on tähelepanu all eelkõige linnaeliit. Sellegipoolest leidub viimasest paarikümnest aastast vähesel määral uurimusi ka kohalike väikelinnade ja alevite kohta. Ilmunud on käsitlusi Pärnu linna ajaloost, samuti Kuressaare alevi ja Narva linna kohta. ${ }^{49}$ Kuivõrd kirjalikke andmeid väikelinnade kohta napib, muudab see iseäranis oluliseks arheoloogilistel kaevamistel saadud leiuandmed. Nii on Haapsalu, Viljandi, Lihula, aga ka Tartu jt linnade keskaja ajaloo uurimises tehtud edusammud sündinud koostöös arheoloogidega. ${ }^{50}$ Huvi väikelinnade ja alevite ajaloo vastu on toitnud Eesti, resp. keskaja Liivimaa linnastumise ja linnavõrgustiku kujunemise uurimine. ${ }^{51}$ Linnade rajamine oli üks tahk murrangulistest muutustest, mis Liivimaal sel ajal aset leidis. Linnaajaloo uurimine on siiski enamasti kulgenud isevoolu teed, sest puudub uurimistöö institutsionaalne koordineerimine; seda suuremat rolli on aga mänginud ajaloolaste huvi suunamisel kohapealne initsiatiiv. Niisamuti on uute uurimuste, iseäranis üldkäsitluste avaldamise tõukeks linna juubelite meelespidamine, näiteks vallandas Tallinna kirjaliku esmamainimise 800. aastapäeva tähistamine 2019. aastal Tallinna ajaloo alaste teoste buumi. ${ }^{52}$

Võrreldes varasema ajaga on 21. sajandil keskaja linnaga tegelevates uurimustes nihkunud fookus majandusajaloo (iseäranis kaubandusajaloo) teemadelt kultuuri-

${ }^{48}$ Eesti linnaehituse ajalugu: Keskajast tsaariaja lõpuni. Peatoim ja koost L. Hansar. Eesti Kunstiakadeemia, Tallinn, 2019. Vt ka Pärn, A. Visandeid keskaegse Lihula vanemast kodanikumajast ja vanemast linnaehitusest. - Vana-Läänemaa ajaloo radadel. Toim M. Mandel. Vana-Läänemaa Ajaloo Selts, Lihula, 2012, 40-53; Kadakas, V. Tallinna Dunkri tänava hävinud kivihoonestusest. - Vana Tallinn, 2015, 26 (30), 11-45; Pärn, A., Russow, E. Kohalik või võõras? Ühe Haapsalu keskaegse hoone tõlgendusest. - Läänemaa Muuseumi toimetised, 2015, 18, 53-70.

${ }^{49}$ Kivimäe, J. Iuravit iuxta formam prescriptam: Zur Rechtslage der Kleinstädte des Bistums ÖselWiek am Ausgang des Mittelaters. - Festschrift für Vello Helk zum 75. Geburtstag: Beiträge zur Verwaltungs-, Kirchen- und Bildungsgeschichte des Ostseeraumes. Hrsg. v. E. Küng, H. Tamman. Eesti Ajalooarhiiv, Tartu, 1998, 119-137; Kivimäe, J. Medieval Narva: Featuring a small town between East and West. - Narva und die Ostseeregion / Narva and the Baltic Sea region. Hrsg. v. K. Brüggemann. TÜ Narva Kolledž, Narva, 2004, 17-29; Põltsam-Jürjo, I. Liivimaa väikelinn UusPärnu 16. sajandi esimesel poolel. Argo, Tallinn, 2009.

${ }^{50}$ Pärn, A. Über die Hausbauentwicklung in Westestland im 13. bis 15. Jahrhundert. - Lübecker Kolloquium zur Stadtarchäologie im Hanseraum III: Der Hausbau. Hrsg. v. M. Gläser. Schmidt-Römhild, Lübeck, 2001, 595-604; Mäesalu, A., Haak, A. Über die Entstehungsgeschichte des mittelalterlichen Dorpats (Tartu). - Lübecker Kolloquium zur Stadtarchäologie im Hanseraum X: Vorbesiedlung, Gründung und Entwicklung. Hrsg. v. M. Gläser, M. Schneider. Schmidt-Römhild, Lübeck, 2016, 507-518.

51 „Hansisch“ oder „,nicht-hansisch“: Das Beispiel der kleinen Städte und Livlands in der Hanse. Hrsg. v. J. Kreem, J. Sarnowsky. (Hansische Studien, 27.) Callidus, Wismar, 2019.

${ }^{52}$ Vt nt: Tallinna ajalugu I: 1561. aastani. Toim T. Kala. Tallinna Linnaarhiiv, Tallinn, 2019. Aastapäeva tähistamisega seoses ilmus 2019. aastal ajalehes Stilus, Tallinna vanemast ajaloost artiklisari, mille põhjal valmis ka raamat, vt: Russow, E. Lood ja leiud Tallinna algusest. Stilus, Tallinn, 2020. 
ja sotsiaalajaloole. Sellest tulenevalt on võrdlemisi tagasihoidlikult realiseeritud Hansa ajaloo potentsiaali rahvusvahelise koostöö edendamisel. Eesti uuemas keskaja uurimises nähakse linna eelkõige kui tähtsat ühenduslüli Euroopa kultuuriruumiga, selle kaudu toimus uute kultuurinähtuste vastuvõtt ja levimine nii linnas kui ka maal laiemalt. Tagaplaanile on jäetud sotsiaalsetele ja etnilistele vastuolude käsitlemine, pigem on seatud eesmärgiks mõista multietnilise ja -kultuurilise linnaühiskonna toimimist suurtest erisustest ja võimalikest vastuoludest hoolimata, ehk leida eri tausta ja sotsiaalse staatusega üksikisikute, samuti ühiskonnagruppide huvide ühisosa, nende koostoimimise võimalusi ja vajadusi.

Tähelepanu on pöördunud linnaühiskonna kujunemisele ja koosseisule, uuritud on linnaelanike organiseerumist kutsealastesse ja usulistesse organisatsioonidesse ning selle kaudu linlaste sotsiaalset mobiilsust. ${ }^{53} \mathrm{Ka}$ linnakodanike identiteet, selle loomine ja väljendusviisid on olnud viljakas uurimisteema. Ajaloolaste huvi on liikunud suurtelt sotsiaalsetelt gruppidel ka üksikisikutele, selleks on kasutatud ajaloolist biograafiažanrit ${ }^{54}$ taotlusega heita pilk keskaja linnale portreelugude kaudu.

Üks suund, mis Eesti 21. sajandi ajalookirjutuses on väga jõudsalt esile tõusnud, on keskaja kultuuriajalugu. Kui veel 1980. aastate lõpul oli Teaduste Akadeemia ühiskonnateaduste osakonna kultuuriloo probleemkomisjonil põhjust nentida, et Eesti kultuuriloo seisukohalt on kõige puudulikumalt valgustatud perioodiks just keskaeg, ${ }^{55}$ siis tänasel päeval võib pigem väita, et just keskaja kultuuriloo historiograafia pakub mitmekülgsemat ja uuenduslikumat pilti kui Eesti ajaloo teiste perioodide oma. Seejuures mõistavad medievistid kultuuri kõige laiemas tähenduses, lähedaselt etnoloogidele ja kultuuriantropoloogidele, kui inimeste kogu vaimsust ja elulaadi, vaateid ja väärtushinnanguid, mis määravad ära sotsiaalse käitumise. Uus arusaamine kultuurist ja kultuuriajaloost, nagu ka püüdlus selle süvendatud uurimise poole, ilmnes tendentsina Eesti ajalooteaduses õigupoolest juba nõukogude aja lõpukümnendeil. ${ }^{56}$ Siiski peeti veel 1980. aastatel kultuuriajaloo teemasid marginaalseks ning ametlikult käsitati kultuuri endiselt kõrgloomingu ja ideoloogiana, ent juba 1990. aastatel ilmusid Eesti keskaja uurimisse uued teemad, nagu argielu- ja mentaliteediajalugu. ${ }^{57}$ Sellealaste monograafiate avaldamiseni jõuti valdavalt siiski alles 2000. aastatel. ${ }^{58}$

${ }^{53}$ Mänd, A. Tallinna Kanuti gild ja selle oldermannid keskajal. — Vana Tallinn, 2005, 16 (20), 129 158; Mänd, A. Suurgildi liikmeskonnast ja kaupmehe sotsiaalsest karjäärist hiliskeskaegses Tallinnas. - Acta Historica Tallinnensia, 2005, 9, 165-187; Mänd, A. Kaupmees Hans Vianti sotsiaalne karjäär, perekond ja kinnisvara. - Vana Tallinn, 2017, 28 (32), 83-114.

${ }^{54}$ Kala, T., Kreem, J., Mänd, A. Kümme keskaegset tallinlast (Tallinna Linnaarhiivi toimetised, 10). Tallinna Linnaarhiiv, Varrak, Tallinn, 2006.

${ }^{55}$ Jansen, E. Kultuuriajalugu ja tänapäev. - Kleio, 1989, 1, 19.

${ }^{56}$ Aarelaid, A., Jansen, E. Rahva kultuurielust minevikus ja tänapäeval. Eesti Raamat, Tallinn, 1982.

${ }^{57}$ Noorte eesti medievistide esimesi sellealaseid uurimusi koondas artiklikogumik: Quotidianum estonicum: Aspects of daily life in medieval Estonia. Ed. by J. Kivimäe, J. Kreem. (Medium Aevum Quotidianum.) Institut für mittelalterliche Realienkunde Österreichs, Krems, 1996. Vt ka Tamm, M. Imeteod ristiusustamisaegsel Liivi- ja Eestimaal (XII sajandi lõpp - XIII sajandi algus). (Tallinna Linnaarhiivi toimetised, 1.) Tallinna Linnaarhiiv, Tallinn, 1996; Vahtre, L. Eestlase aeg: Uurimus eesti rahvapärase ajaarvamise ajaloost. 2. tr. Varrak, Tallinn, 2000.

${ }^{58}$ Põltsam-Jürjo, I. Söömine-joomine keskaegses Tallinnas. Argo, Tallinn, 2002; Mänd, A. Pidustused keskaja Liivimaa linnades 1350-1550. (Tallinna Linnaarhiivi toimetised, 7.) Eesti Keele Siht- 
Keskaja kultuuriajaloo uurimine on Eestis hargnenud paljudesse suundadesse, hõlmatud on argikultuur (nt toit, peod, rõivastus, ajakasutus, lapsepõlv jne), ${ }^{59}$ usuelu ${ }^{60}$ visuaal- ja materiaalne kultuur, ${ }^{61}$ mäletamisviisid,${ }^{62}$ kirjakultuur, sh eesti kirjakeele kujunemine ${ }^{63} \mathrm{jpm}$. Kuivõrd keskaja Liivimaal segunesid ja põimusid

asutus, Tallinn, 2004; Mänd, A. Urban carnival: Festive culture in the Hanseatic cities of the Eastern Baltic, 1350-1550. Brepols, Turnhout, 2005.

${ }^{59}$ Mänd, A. Linlased ja rüütlikultuur: kaupmeeste võitlusmängud keskaegses Tallinnas ja Riias - Vana Tallinn, 2002, 13 (17), 141-158; Põltsam, I. Vaeste hoolekanne Tallinnas (1346-1561) - Vana Tallinn, 2002, 13 (17), 174-190; Põltsam-Jürjo, I. Vakupeost keskaja Liivimaal. - Tuna, 2007, 4, 11 28; Russow, E. Baden im kalten Wasser im Sommer und Schneeballwerfen im Winter streng verboten: Kindheit und Jugend in Reval (Tallinn) nach mittelalterlichen und frühneuzeitlichen Quellen. - Lübecker Kolloquium zur Stadtarchäologie im Hanseraum: Kindheit und Jugend. Hrsg. v. M. Gläser. Schmidt-Römhild, Lübeck, 2012, 419-432; Põltsam-Jürjo, I. Kellele kuulub öö? Elust pimedal ajal 13.-16. sajandi Liivimaal. - Tuna, 2014, 4, 14-32; Mänd, A. Horses, stags and beavers: Animals as presents in late-medieval Livonia - Acta Historica Tallinnensia, 2016, 22, 3 17; Põltsam-Jürjo, I. Siga, seapidamine ja sealiha toiduks tarvitamine Eestis 13.-16. sajandil. Tuna, 2017, 4, 8-24 ; Põltsam-Jürjo, I. Lastest ja lapsepõlvest 13.-16. sajandi Eestis. - Vana Tallinn, 2017, 28 (32), $115-146$.

${ }^{60}$ Vunk, A. Jeesus läks maal kõndimaile: Ristisõjad ja palverännakud Eesti keskajal. Argo, Tallinn, 2005; Kala, T. Keskaegse Tallinna väikekorporatsioonid ja nende usuelu normatiivsed vormid. Tuna, 2010, 2, 6-24; Jonuks, T., Joosu, L. Pendants of St. Anthony cross with the crucifixion from Estonia: Possible badges of a folk pilgrimage. - Estonian Journal of Archaeology, 2013, 17, 123 138; Selart, A. Ristiinimese ristinimi: „,Kristlikest“ nimedest 13. sajandi Eestis. - Läänemaa Muuseumi toimetised, 2016, 19, 2-22.

${ }^{61}$ Vunk, A. Mentaliteedi peegeldus Pärnu kahlileidudel: Linnaarheoloogia teoreetilisi aspekte. - Eesti Arheoloogia Ajakiri, 2000, 4 (2),151-174; Russow, E. Haruldane habemik Toompealt. - Linnusest ja linnast: Uurimusi Vilma Trummali auks. Toim A. Haak, E. Russow, A. Tvauri. (Muinasaja Teadus, 14.) Eesti Teaduste Akadeemia Kirjastus, Tartu, Tallinn, 2004, 317-331; Russow, E. Importkeraamika Lääne-Eesti linnades 13.-17. sajandil. Tallinna Ülikooli ajaloo instituut, Tallinn, 2006; Bome, H. The „marginal“ motifs of Karja church - magical or mystical. - Bilder i marginalen: Nordiska studier i medeltidens konst / Images in the margins: Nordic studies in medieval art. Ed. by K. Markus. Argo, Tallinn, 2006, 223-234; Mänd, A. Kirikute hõbevara: Altaririistad keskaegsel Liivimaal. (Eesti kirikute sisustus, 1.) Muinsuskaitseamet, Tallinn, 2008; Kurisoo, M. Ristimise läte: Ristimiskivid keskaegsel Liivimaal. (Eesti kirikute sisustus, 2.) Muinsuskaitseamet, Tallinn, 2009; Jonuks, T., Friedenthal, M., Haak, A. Värtnakeder, talisman või nõiaese - märkidega kiviketas Viljandimaalt. - Ilusad asjad. Toim Ü. Tamla. (Muinasaja Teadus, 21.) Tallinna Ülikooli ajaloo instituut, Tallinn, 2010, 2, 269-286; Kunstiteaduslikke Uurimusi, 2016, 25, 1-2, erinumber „Keskaegse Liivimaa visuaalkultuur“. Koost A. Randla; Mänd, A. Keskaegsed altarid ja retaablid. (Eesti kirikute sisustus, 4.) Muinsuskaitseamet, Tallinn, 2019.

${ }^{62}$ Mänd, A. Naised, memoria ja sakraalruum hiliskeskaegsel Liivimaal - Tuna, 2012, 3, 6-29; Mänd, A. Visuaalne mälestamine: Liivimaa ordumeistrite ja käsknike hauaplaadid (14.-16. sajand). - Kunstiteaduslikke Uurimusi, 2019, 28, 3-4, 60-93; Mäesalu, M. Historical memory as the cause of conflict in medieval Livonia. - Vestnik of Saint Petersburg University. History, 2019, 64, 3, 1014-1030.

${ }^{63}$ Kala, T. Euroopa kirjakultuur hiliskeskaegsetes õppetekstides: Tallinna dominiiklase David Sliperi taskuraamat. Tallinna Linnaarhiiv, Tallinn, 2001; Tamm, M. Kloostriraamatud keskaegses Euroopas ja Eestis. - Kloostrist Internetini. Toim T. Tender. Eesti Raamatu Aasta Peakomitee, Tartu, 2001, 46-83; Friedenthal, M. Millisest kontekstist pärineb Tallinna Linnaarhiivi käsikiri Cm3? - Ajalooline Ajakiri, 2008, 1-2, 5-28; Kivimäe, J. Eesti keele kaja Helmich Ficke kaubaraamatus 15361542. - Keel ja Kirjandus, 2009, 8-9, 583-594; Kala, T. Keskaegse Liivimaa kirikliku kirjasõna hulgast ja laadist. - Konfessioon ja kirjakultuur. Toim P. Lotman. (Acta Bibliothecae Nationalis 
pärismaised ja sissetoodud kultuuritavad, siis eitamata piiri ja isegi vastuolude olemasolu ja püsimist nende vahel, keskenduvad nüüdisaja käsitlused pigem eri kultuuride koosmõju, kooseksisteerimise ja kultuurielementide vastastikuse ülevõtmise uurimisele. ${ }^{64}$ Viimastel aastatel on uurimine eriti koondunud identiteediküsimuste ümber, mitmesuguseid narratiive, rituaale ja sümboleid on vaadeldud kui kohalikku ühiskonda ja väiksemaid sotsiaalseid gruppe konstitueerivaid elemente. ${ }^{65}$ Samas pole loobutud ka nn kõrgkultuuri käsitlusest, kui mainida siinkohal kas või üleeuroopalise tähtsusega maalikunstniku Michel Sittowi isikut, karjääri ja loomingut puudutavaid uurimusi. ${ }^{66}$

\section{ALLIKATE PUBLITSEERIMINE}

Linnaajaloo, nagu üldse keskaja Liivimaa ajaloo uurimise juurde on alati loomuliku koostisosana kuulunud allikate publitseerimine. 21. sajandil on sellega tegeletud suhteliselt sporaadiliselt, enamasti on selle taga olnud üksikute uurijate initsiatiiv; ühtne või koordineeritud, samuti institutsionaalne tegevus selles valdkonnas puudub. Eraldi suuremaid allikapublikatsioone on ilmunud vaid üksikuid, pigem on allikaid publitseeritud monograafia ${ }^{67}$ või artikli lisana. ${ }^{68}$ Linnaajaloo allikate publitseerimist on eelkõige toetanud Tallinna Linnaarhiiv, ${ }^{69}$ linnavõimude otsene materiaalne toetus nii teadusspetsiifilistele väljaannetele on pigem erand. ${ }^{70}$ Laia ajaloohuvilise auditooriumi tarvis on avaldatud keskaja

Estoniae, 15.) Eesti Rahvusraamatukogu, Tallinn, 2016, 13-40; Kala, T. Eesti keel pärisnimede ja etnonüümide näitel mõnedes varauusaegsetes Tallinna allikates. - Vana Tallinn, 2017, 28 (32), 57 82; Kolk, K. Eesti kloostrite raamatud enne ja pärast reformatsiooni. - Reformatsioon - tõlked ja tõlgendused, 71-112.

${ }^{64}$ Nt Estnisches Mittelalter: Sprache - Gesellschaft - Kirche. Hrsg. v. K.-R. Hahn, M. Thumser, E. Winkler. (Schriften der Baltischen Historischen Kommission, 20.) Lit, Berlin 2015.

${ }^{65}$ Vt nt Selart, A., Mänd, A. Livonia - a region without local saints? - Symbolic identity and the cultural memory of saints. Ed. by N. H. Petersen, A. Mänd, S. Salvadó, T. R. Sands. Cambridge Scholars Publishing, Newcastle upon Tyne, 2018; Kala, T. Regional und trans-regional traditions in saints' cults: A Dominican calendar from late medieval Tallinn. - Symbolic identity and the cultural memory of saints, $123-144$

${ }^{66}$ Mänd, A. Michel Sittow and Reval (Tallinn): A new look at records in the Tallinn City Archives. Michel Sittow 1469-1525: The artist connecting Estonia with the Southern Netherlands. Ed. by T. Abel. The Art Museum of Estonia, Tallinn, 2001, 3-13. Vrd ka: Mänd, A. Bernt Notke - uuenduste ja traditsioonide vahel / Bernt Notke - between innovation and tradition. Eesti Kunstimuuseum, Tallinn, 2010; Michel Sittow: Estonian painter at the courts of Renaissance Europe. Ed. by J. Strand. National Gallery of Art, Washington, and the Art Museum of Estonia, Washington, 2017.

${ }^{67} \mathrm{Nt}$ Mänd, A. Kirikute hõbevara, 180-224.

${ }^{68} \mathrm{Vt}$ nt Leimus, I. Kalakaupleja ja tema naine: Pilguheit ühe Tallinna mittesaksa paari elujärge 1550. aastal. - Ajalooline Ajakiri, 2014, $2 / 3$ (148/149), 251-264.

${ }^{69}$ Kaupmees Matheus Spielmanni arveraamatud 1568-1570 / Rechnungsbücher des Kaufmanns Matheus Spielmann von 1568-1570. Toim I. Leimus. (TLA toimetised, 15.) Tallinna Linnaarhiiv, Tallinn, 2017.

${ }^{70}$ Pärnu linna ajaloo allikad 13.-16. sajandini / Quellen zur Geschichte der Stadt Pernau 13.-16. Jahrhundert. Toim I. Põltsam, A. Vunk. Pärnu Muuseum, Pärnu, 2001. 
allikate tõlkeid eesti keelde, kõige nimetamisväärsem on Liivimaa vanema riimkroonika tõlge, samuti Tallinna ajaloo lugemikus ilmunud keskaja allikate osa. ${ }^{71}$ Tõsi on, et keskaja allikate lausdigiteerimise olukorras, samuti tehnoloogiliste võimaluste pideva avardumise surve all nõuab allikate publitseerimine, selle eesmärgid, viis ja meetodid paratamatult ümbermõtestamist. Samas ei saa aga - arvestades, millist rolli mängivad ka tänapäeval kas või baltisaksa ajaloolaste poolt 19. sajandil ja 20. sajandi algul koostatud ja avaldatud ürikuteraamatud keskaja Liivimaa ajaloo uurimisel - allikapublikatsioonide teema olulisusest ja jätkuvast aktuaalsusest kuidagi mööda vaadata. On vaieldamatu tõsiasi, et selles valdkonnas on üksnes lühiajaliste projektidega ning püsiva institutsionaalse toeta vähegi kaalukamate tulemusteni jõuda võimatu. Eesti keskaja ajaloo uurimise hea ja ajakohane kvaliteet, samuti võimalikud uuendused ei ole aga saavutatavad ilma eri allikaliikidel põhinevate andmebaaside ja editsioonide koostamise järjepideva tööta. Paraku jätkavad ürikuteraamatut praegu tänuväärselt Saksa teadlased, ${ }^{72}$ sest Eestis sellekohane majanduslik ja organisatoorne võimekus lihtsalt puudub. Küsimus pole mitte pelgalt üha uute allikate publitseerimises - ka mitmed vanemad, kuid sellegipoolest aktiivselt kasutatavad allikaeditsioonid on tegelikult lootusetult vananenud ${ }^{73}$ ja vajaks hädasti uusväljaannet.

\section{VAHEKOKKUVÕTE KESKAJA UURIMISEST}

Kui võrrelda Eesti keskaja-uurimist 20. ja 21. sajandil, siis võib veel üheks üldisemaks suundumuseks pidada, et uurijad ei keskendu enam ainult üksikutele teemavaldkondadele, vaid tegelevad nii mitme kitsama ajaperioodiga kui ka erinevate allikate ja küsimusteringidega. Samuti on tähelepanuväärne nii „puhta“ ajaloo ja kunstiajaloo $^{74}$ kui ka ajaloo ja arheoloogia küsimuseasetuste ja meetodite põimumine. ${ }^{75}$ Institutsionaalselt on Eesti keskaja-ajaloolased seotud eelkõige kolme asutusega - Tartu Ülikooli, Tallinna Linnaarhiivi ja Tallinna Ülikooliga. Viimasega

${ }^{71}$ Liivimaa vanem riimkroonika. Tlk U. Eelmäe. Argo, Tallinn, 2003; Tallinna ajaloo lugemik: Dokumente 13.-20. sajandini. Toim L. Kõiv jt. (TLA toimetised, 14.) Tallinna Linnaarhiiv, Tallinn, 2014.

${ }^{72}$ Vt Liv-, Est- und Kurländisches Urkundenbuch, Erste Abteilung, Bd. 13: 1472-1479. Hrsg. v. K. Neitmann, M. Thumser. Böhlau, Köln, 2018; Liv-, Est- und Kurländisches Urkundenbuch, Erste Abteilung, Bd. 14: 1480-1483. Hrsg. v. K. Neitmann, M. Thumser. Böhlau, Wien, 2020; vrd Thumser, M. Die Quellen. - Das Baltikum: Geschichte einer europäischen Region, Bd. 1: Von der Vor- und Frühgeschichte bis zum Ende des Mittelalters. Hrsg. v. K. Brüggemann, R. Tuchtenhagen, D. Henning, K. Maier. Anton Hiersemann, Stuttgart, 2018, 145-158.

${ }^{73}$ Vrd Kala, T. Friedrich Georg von Bunges Quelleneditionen zur Geschichte der russischen Ostseeprovinzen und das Revaler Ratsarchiv. - Blätter für deutsche Landesgeschichte, 2017, 152, 343-367.

${ }^{74}$ Nt Markus, K. Visual culture and politics in the Baltic Sea region, 1100-1250. (East Central and Eastern Europe in the Middle Ages, 450-1450, 63.) Brill, Leiden, 2020.

${ }^{75} \mathrm{Vt}$ nt Valk, H. Vasalles or seniores? The old nobility and new power structures in post-conquest Estonia. - Viking Heritage Magazine, 2002, 1, 22-24; Russow, E. Moest, mugavusest ja veendumustest kesk- ja varauusaja Soomes. - Estonian Journal of Archaeology, 2011, 15, 73-79. 
ühendati 2005. aastal eraldi üksusena ja 2015. aastal lõplikult varasem Ajaloo Instituut. Tallinna Ülikooli juures tegutseb alates 2005. aastast keskaja keskus, mis koondab medieviste üle Eesti, sh ajaloolasi, kunstiajaloolasi ja arheolooge; mitmesuguste akadeemiliste tegevuste kõrval on keskaja keskuse tähtsaks väljundiks liikmete teadustöö tulemuste populariseerimine. ${ }^{76}$ Olulist osa uurimistöö suunamisel objektidele väljaspool Tallinna ja Tartut ning tulemuste tutvustamisel on etendanud tugevama teadusliku sihiseadega kohalikud muuseumid. ${ }^{77}$ Väga tähtsal kohal on rahvusvaheline koostöö, mille regionaalse organina tuleb ära mainida Balti Ajaloo Komisjon. ${ }^{78}$

Asjatu oleks eitada Eesti teaduspoliitikas valitseva projektipõhisuse põhimõtte mõju keskaja ajaloo uurimisele, selles võib leida nii positiivseid kui ka negatiivseid aspekte. Ühest küljest on see sundinud medieviste otsima uusi koostöövorme ja väljundeid, millest on lõpptulemusena sündinud paljugi uuenduslikku, näiteks mitme distsipliini esindajaid koondavad uurimisrühmad, interdistsiplinaarsed käsitlused, ühisartiklid ja ühiselt kirjutatud köited, samuti võõrkeelsed rahvusvahelised kogumikud. Suured projektid on Eesti 21. sajandi medievistikas paratamatult dikteerinud teemasid ja uurimissuundi, olgu selleks siis koloniseerimine, Euroopa kultuurimõjud või keskuse-ääremaa suhted. ${ }^{79}$ Projektipõhisuse mõju ulatust Eesti keskaja uurimisele demonstreerib hästi aastatel 2014-2019 töös olnud teema „Liivimaa kujunemine: toimijad, institutsioonid ja võrgustikud kesk- ja varauusaegses Läänemere regioonis“, mis koondas endas pretsedenditul arvu, s.o koguni kolmteist medievisti (ajaloolast, kunstiajaloolast ja arheoloogi). Samas sunnib projektide lühiajalisus ja publitseerimissurve uurijatele peale ühetaolisi raame oma uurimistöö tulemuste esitamiseks. Selle tagajärjel on vähenenud monograafiate osatähtsus ja prestiiž nn punktiartiklite ees, samuti ei ole teadusbürokraatia piisavalt hinnanud ajaloo populariseerimist.

Üheks kõige olulisemaks tähiseks Eesti keskaja uurimises on kahtlemata Eesti ajaloo teise köite ilmumine 2012. aastal. Viimane võrreldav teos nägi trükivalgust kolmveerand sajandi eest - 1937. aastal. Ühest küljest koondas üldkäsitluse autorkond endas keskaja uurijate tuumikut, teisalt oli tegu kokkuvõttega 10-15 aasta jooksul tehtud töö tulemustest ning ülevaatega aktuaalsetest suundumustest keskaja uurimises. Võrreldes 20. sajandi esimese poole Eesti ajaloo väljaannetega on 21. sajandi teoses rõhk Eesti ühiskonna seostel Euroopaga, s.t vaadeldakse Eesti poliitilisi, majanduslikke ja kultuurilisi seoseid muu maailmaga. Nagu põhjendatult on sedastatud üldkäsitluse sissejuhatuses, tuleneb see oluliselt tänapäevastest ühiskondlik-poliitilistest suundumustest: „Viimasel kümmekonnal aastal on Eesti kesk-

${ }^{76} \mathrm{Nt}$ 2019. aasta märtsis ilmus keskaja keskuse liikmete ühistöö viljana ajakirja Horisont erinumber, mis on pühendatud Eesti keskaegsele linnakultuurile.

${ }^{77} \mathrm{Nt}$ SA Haapsalu ja Läänemaa muuseumid (Läänemaa Muuseumi toimetised).

${ }^{78}$ Kreem, J., Misāns, I. Der Blick aus dem Baltikum: Estland, Lettland und die Baltische Historische Kommission. - Blätter für Deutsche Landesgeschichte, 2017, 153, 387-404.

${ }^{79}$ Vt SF0130019s08 „Kristianiseerimine, koloniseerimine ja kultuurivahetus: Eesti Euroopaidentiteedi ajaloolised lätted (13.-17. sajand)“ (2008-2013); PUT107 „Keskaegne Liivimaa: Euroopa ääremaa ja tema keskused (12.-16. sajand)“(2013-2016); PUT1422 „Ühiselu, eraldatus ja kultuuriline vastasmõju keskaegsel Liivimaal (1200-1550)“(2017-2020). 
aja käsitust tõenäoliselt kõige enam mõjutanud Euroopa Liidu laienemis- ja lõimimisprotsess" ${ }^{\text {“ }}{ }^{80}$ Keskaja uurimise tihenenud rahvusvaheline integratsioon on toonud kaasa hinnangute korrigeerimise keskaja kui ajalooperioodi suhtes, samuti uued rõhuasetused ja meetodid uurimistöös. Keskaja ajaloo poleemilist potentsiaali ja olulisust ühiskondlikus mälus näitas raamatu ilmumisele järgnenud reaktsioon, mis paljastas lõhe avalikkuse ootuse ja ajalooteaduse nüüdisaegse arengu vahel. Eesti euroopastumise uurimise tõstmisel keskaja ajaloo käsitluse keskpunkti, väärib äramärkimist ja annab järelemõtlemiseks ainet Ea Janseni 1997. aastal väljendatud seisukoht: „Ilmselt on lausa kompleksiks kujunenud kartus, et me ikkagi ei kuulu või ei kuulu küllaldaselt - Euroopasse." Ta osutab, et vähemalt Ado Grenzsteini aegadest on see olnud eesti haritlaskonna lakkamatu mure, kuigi isegi ei defineerita, mida Euroopa all õieti mõistetakse. ${ }^{81}$

Lääne-Euroopa ajalooteaduse mõjul on Eestiski 20. sajandi lõpust alates tegeletud moodsate ja uudsete teemadega (mikroajalugu, sooajalugu, suuline ajalugu, mälukultuur, loomaajalugu jne), samuti on juurutatud nende teemadega seonduvat terminoloogiat (nt „toimija“, „transkultuurilisus“). See on võimaldanud dialoogi ning vajadusel ka diskussiooni teiste maade ajaloolaste ja ajalookirjutusega. Teisest küljest ei saa eitada, et pelgalt muu maailma ajalooteaduse tuules liikumine võib pärssida kohalikke uuendusi, nii metodoloogilisi kui ka sisulisi, mis tuleneks kohaliku allikabaasi ja ajaloolise arengu eripäradest. Need on kaks ülesannet, millega Eesti medievistika peab paratamatult ka edaspidi toime tulema.

\title{
TÄNUAVALDUS
}

Artikkel on valminud teadusprojektide IUT31-6 „Eesti ajaloo rahvusülene raamistik: transkultuurilised põimingud, ülemaailmsed organisatsioonid ja piiriülene ränne (16.-21. saj)“ “ja PUT 1422 „Ühiselu, eraldatus ja kultuuriline vastasmõju keskaegsel Liivimaal (1200-1550)“ raames.

\section{ESTONIAN MEDIEVAL RESEARCH IN THE TWENTY-FIRST CENTURY}

\author{
Inna PÕLTSAM-JÜRJO and Anti SELART
}

Medieval research in Estonia before the 1990s concentrated mainly on the history of peasants and agriculture. The new generation of historians who generally studied at the University of Tartu in the 1980s and 1990s substantially changed this situation. The amount of medieval research increased significantly, and the scope of research topics became much wider. Over the last two decades, medieval research in Estonia has discovered several new ways of history writing, such as microhistory, gender

\footnotetext{
${ }^{80}$ Eesti ajalugu II, 15.

${ }^{81}$ Jansen, E. Hajamõtteid Eesti ajaloo uurimisest. - Kleio, 1997, 1 (19), 38.
} 
studies, oral history, the history of animals, etc., which have undoubtedly brought richer and more diverse knowledge about medieval history. This also enabled historians to provide a more comprehensive picture of society and the social, cultural, etc., development of Livonia in the Middle Ages.

Due to the active international co-operation, supported by the political changes in Europe at the end of the twentieth century, medieval Livonia increasingly became a topic of interest for scholars outside Estonia and Latvia. Over the last two decades the publication activity (including publications in foreign languages) of Estonian medievalists increased several times and certainly represents one of the most active and deeply internationally networked fields of the Estonian humanities.

The central areas of medieval research in the 2000s and 2010s have been the Baltic Crusades, the history of the Teutonic Order, social history dominantly in the urban context, and the history of everyday culture. The outcome of interdisciplinary cooperation between historians, archaeologists and art historians has become important. A remarkable general tendency that can be observed is the more integrative presentation of medieval Livonian society compared to the traditional understanding. Research tends to stress interaction and mutual cultural impact between social and ethnic groups instead of conflict and isolation. The political history of medieval Livonia is dominated by examination of the activities of the Livonian Teutonic Order, and here it is remarkable that scholars have detailed account of the personal and political connections of individual actors outside Livonia, with the papal curia or emperor, for example.

As the Tallinn City Archives are one of the best-preserved medieval archives in the Hanse area, urban history and the history of Tallinn deserve closer attention. Scanty written sources make research into small towns a convoluted and sometimes even impossible task. Luckily, the absence of written records is sometimes compensated for by archaeological findings, which makes cooperation between historians and archaeologists in this research field necessary. Medieval research in Estonia has also focused on important ecclesiastical and religious processes, especially on the spread of the Lutheran Reformation in Livonia. Regarding both urban and rural populations, the themes of everyday life, such as food or festivals, became more important than traditional interest in international trade or agricultural productivity. The lack of personal and material resources has limited the work on medieval source publications. In this regard the digital age is without doubt a major new challenge to Estonian medievalists, and, furthermore, leads to innovative approaches to medieval history. 